\title{
Public Perception of Fine Dust: A Comparative Re- search of Participation Motives in Outdoor Physical Activities Depending on Fine Dust Concentration
}

\author{
Chulhwan Choi ${ }^{1}$ and Chul-Ho Bum ${ }^{2}$
}

${ }^{1}$ Kyung Hee University, Department of Golf Industry, College of Physical Education, Yongin, Korea, ${ }^{2}$ Kyung Hee University, Department of Sports Taekwondo, Graduate School of Physical Education, Yongin, Korea

\begin{abstract}
Since the concentration of fine dust concentration in the atmosphere is rapidly increasing, recently to severe levels, and it has a fatal effect on human health, a change in people's awareness of outdoor physical activities is necessary. Nevertheless, people still take part in outdoor physical activities, even on days when a fine dust risk alert is issued, which shows that people's awareness of the danger of fine dust to their health is still lacking. This study used 341 surveys that was conducted to analyze and compare people's motives for participation in physical activities in relation to the fine dust level. After an exploratory factor analysis and reliability analysis using SPSS 23.0, the level of fine dust concentration in the atmosphere was divided into "dangerous" and "normal," while the respondents to the survey were divided into a "with fine dust group" and a "without fine dust group." People's participation motives were compared and analyzed by using a multivariate analysis of variance (MANOVA). People who participated in outdoor physical activities on days with a severe fine dust concentration showed higher scores for the motives of Competition, Appearance, Physical Condition, and Mastery, while those who participate in outdoor physical activities on days without a find dust alert showed higher scores for the motive of Psychological Condition. Countermeasures against the danger of fine dust that are more effective should be established by analyzing the motives of people who participate in outdoor physical activities despite the dangerous level of fine dust concentration in the atmosphere.
\end{abstract}

Key words: particulate matter $\left(P M_{10}\right)$, physical activity, participation motives, public health

\section{Introduction}

Climate change is a natural phenomenon that cannot be controlled by humans, and it involves a significant part of our everyday lives (Kim, 2018). Human life is greatly affected not only by major natural phenomena, such as earthquakes or hurricanes, but also by minor changes in climate such as hot or cold weather. In addition, environmental pollution caused by human beings has become the greatest global challenge and a problem that requires everyone to find a solution. Abnormal global climate patterns, including heavy snow, heatwaves, and heavy rain, are posing a significant threat to human be- ings (Berry, Waite, Dear, Capon, \& Murray, 2018). Recently, the amount of fine dust in the atmosphere has been passing an acceptable level, due to pollutants generated by factories, dust generated at construction sites, and the large number of vehicles, all the consequence of industrialization (Noh, Lee, \& Yu, 2018; Stone, Yoon, \& Schauer, 2011).

Fine dust $\left(\mathrm{PM}_{10}\right)$ has a very fine particle size that cannot be seen by the human eye; it is a pollutant only $10 \mu \mathrm{m}$ in size ( 1 $\mu \mathrm{m}$ equals to $1 / 1,0001 \mathrm{~mm}$ ) (Kang, 2016). Kwak (2019) explained the serious health impact of fine dust as follows. First, fine dust causes an inflammatory response in the bronchial tubes,

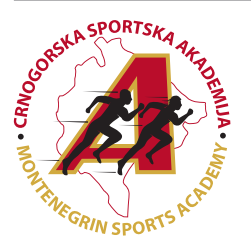

Correspondence: 
with negative effects in the respiratory system, such as chronic bronchitis, allergic rhinitis, and respiratory obstruction. In addition, it can cause or aggravate cardiovascular diseases, such as stroke, heart attack, and heart rate anomaly. The Korea Environment Corporation (K-eco) (2018) recently tightened the criteria for fine dust alerts into "good" for $0-15 \mu \mathrm{g} / \mathrm{m}^{3}$ of fine dust concentration; "average" for $16-35 \mu \mathrm{g} / \mathrm{m}^{3}$; "bad" for $36-75 \mu \mathrm{g} / \mathrm{m}^{3}$; and "very bad" for $76 \mu \mathrm{g} / \mathrm{m}^{3}$ or higher. Since air pollution can have fatal consequences for human beings, who cannot live without air, many countries around the world are endeavoring to reduce fine dust (J. Park, E.H. Park, Schauer, $\mathrm{Yi}, \& \mathrm{Heo}, 2018)$. The Korean government is measuring air pollutant concentration and implementing a system of fine dust alerts. The government suggests dos and don'ts for citizens according to the fine dust concentration level. Notably, Korea is also implementing a total pollutant load system for businesses in order to control the fine dust emanating from industrial establishments, expanding the supply of low-pollution vehicles, strengthening global cooperation with other countries, and implementing joint studies with them to curb environmental pollution. Despite such efforts, the maximum hourly average concentration of fine dust on the days of fine dust alerts has consistently increased, from $192 \mu \mathrm{g} / \mathrm{m}^{3}$ in 2014 to $245 \mu \mathrm{g} / \mathrm{m}^{3}$ in $2015,373 \mu \mathrm{g} / \mathrm{m}^{3}$ in 2016 , and $423 \mu \mathrm{g} / \mathrm{m}^{3}$ in 2017 (Yonhap News, 2019). Consequently, the government recommends that people refrain from outdoor activities on the days when a fine dust alert is issued, but many people still engage in outdoor activities, even without wearing masks, on days of severe fine dust concentration.

Many studies have suggested that outdoor physical activities bring many advantages, regardless of fine dust. Previous researchers have found that greater leisure participation may provide various physical benefits. In particular, given that regular physical activity participation allows people to reduce their negative cholesterol, obesity, high blood pressure, and diabetes, it has been suggested that they avoid sedentary leisure activities (Kemperman \& Timmermans, 2008). These physical health benefits will lead to better mental health with strengthened self-efficacy (Priest, Armstrong, Doyle, \& Waters, 2008) and will reduce stress (Henderson \& Bialeschki, 2008). Previous research has also revealed that leisure participation is the best way of reducing work-related stress because of (a) its challenging nature and (b) its more recuperative nature (Trenberth \& Dewe, 2002). Furthermore, the positive results related to physical and mental benefits can make individuals into valued members of society (Kim, Dattilo, \& Heo, 2011). According to Ingen and Eijck (2009), given that leisure activity participation may improve a person's social network, such activities can have a positive influence on social capital.

Despite the fact that outdoor activities performed when fine dust alerts are issued may have more disadvantages than advantages, many people still work out outdoors on such days, without any sense of concern. However, they should reconsider doing outdoor activities on days of severe air pollution. Participation in leisure and sports can entail regular engagement in physical activities, with a positive impact on people's psychological well-being (Roychowdhury, 2018). Therefore, it is true that the motive for participating is regarded as a very important factor in people's continuous participation in leisure activities (Frederick-Recascino \& Morris, 2004; Lloyd-Jones et al., 2010). People exhibit various motives for participation in leisure activities, including fun, enjoy- ment, health, a sense of achievement, and communication with other people (Bandura, 1997; Gaston-Gayles, 2005; Mouratadis, Vansteenkiste, Lens, \& Sideridis, 2008; Murcia, Coll, Martin-Albo, \& Gimeno, 2010; Waldron \& Dieser, 2010). By contrast, those who do not derive any fun from sports activities, who have trouble with sports coaches, or who are excessively obsessed with winning tend to discontinue their participation in leisure and sports activities (Weiss \& Ferrer-Caja, 2002). In addition, gender is also a factor that affects the motive for participation. After conducting a questionnaire survey on students, Egli, Bland, Melton, and Czech (2011) reported that male students have a tendency to participate in leisure and sports activities due to intrinsic factors, such as the competition and challenge involved, whereas female students participate for weight or appearance management. In conclusion, people have their own motives for participating in leisure and sports activities and for continuing or discontinuing with those activities (Ntoumanis, 2005). However, regardless of the diverse demographic factors that have been used by other studies, given the fine dust levels that have emerged as the biggest social issue of the present day, it is extremely urgent that a study on the outdoor physical activities of people be conducted.

Therefore, the purpose of this study is to analyze the differences in the motives of people who participate in outdoor physical activities on the days when an air pollution (fine dust) alert has been issued, as well as on other days when the air quality was fine. By doing so, it will explore the motives of people to engage in outdoor physical activities on days with different fine dust levels. The results of this study will contribute to the understanding of people's awareness of fine dust and to establishing effective countermeasures. To this end, the study has posed the following research question: What are the differences in participation motives for physical leisure activities according to fine dust concentration?

\section{Methods}

\section{Participants and data collection}

To investigate the differences in participation motives according to fine dust concentration, this study conducted a survey of people who participate in outdoor physical activities (such as walking, jogging, and cycling). The survey was conducted in the Han River National Park, located in Seoul, Republic of Korea. The survey targeted people who enjoyed various outdoor physical activities. It took approximately 10 minutes for a respondent to complete the survey, and all respondents voluntarily completed it through a self-administration method.

To meet the research design, the data collection procedure was performed on the basis of air pollution in terms of fine dust. The questionnaire survey was conducted separately for a period when the fine dust alert, including the two-day rotation system for vehicles and a warning to refrain from outdoor activities was issued (January 14/15, March 26 in 2018, January $14 / 15$ in 2019), and for a period when the fine dust concentration level was "good" or "average" (August 2018). A total of 430 surveys were distributed, and 359 were collected (an approximately $83.5 \%$ response rate). After excluding 18 incomplete surveys, 341 surveys were utilized in this research. On the basis of the fine dust concentration, this study divided survey respondents into two groups: (a) with fine dust $(\mathrm{n}=140,41.1 \%)$ and (b) without find dust $(\mathrm{n}=201,58.9 \%)$. 


\section{Measures}

To measure the participation motives the Physical Activity and Leisure Motivation Scale utilized in the study by Molanorouzi, Khoo, and Morris (2014) was revised and used accordingly. The instrument had revealed acceptable reliability scores (a Cronbach's alpha level of 0.78 to 0.81 ) in the previous study. The seven subfactors-(a) Competition (three items), (b) Appearance (four items), (c) Affiliation (three items), (d) Physical Condition (four items), (e) Psychological Condition (four items), (f) Mastery (three items), and (g) Enjoyment (four items) - had a total of 25 items measured on a 7-point Likert scale, ranging from 1 ("Strongly disagree") to 7 ("Strongly agree"). With the instruments above, a multivariate analysis of variance (MANOVA) was conducted to compare and analyze the differences in the participation motives of outdoor physical activities based on atmospheric fine dust concentration.

\section{Results}

Descriptive statistics

The first group (with fine dust) consisted of 86 (61.4\%) male and $54(38.6 \%)$ female participants. In terms of age, $27.9 \%(n=39)$ were in their 20 s, the largest group, followed by those in their $30 \mathrm{~s}(\mathrm{n}=34,24.3 \%)$, over-60 s $(\mathrm{n}=31$, $22.1 \%), 40 \mathrm{~s}(\mathrm{n}=23,16.4)$, and $20 \mathrm{~s}(\mathrm{n}=13,9.3 \%)$. In relation to sports participation, survey respondents engaged in Walking ( $\mathrm{n}=38,27.1 \%)$, Jogging $(\mathrm{n}=34,24.3 \%)$, and Cycling $(n=29,20.7 \%)$. The results also revealed that all respondents $(n=140,100 \%)$ in this group checked the weather report for the fine dust concentration before participating in their activities, and $73.6 \%(\mathrm{n}=103)$ wore dust filter masks.

The second group (without fine dust) consisted of 96 (47.8\%) male and 105 (52.2\%) female participants. With regard to age, $24.4 \%(\mathrm{n}=49)$ were in their $50 \mathrm{~s}$, the largest group, followed by those in their $30 \mathrm{~s}(\mathrm{n}=47,23.4 \%)$, over- $60 \mathrm{~s}$ (n 40, 19.9\%), $20 \mathrm{~s}(\mathrm{n}=34,16.9 \%)$, and $50 \mathrm{~s}(\mathrm{n}=31,15.4 \%)$. Most respondents participated in Jogging $(n=54,26.9 \%)$, Walking ( $\mathrm{n}=52,25.9 \%)$, and Cycling $(\mathrm{n}=42,20.9 \%)$. In addition, $73.1 \%$ of respondents $(n=147)$ in this group checked the concentration of fine dust, while $24.4 \%(n=49)$ wore dust filter masks. More detailed information is shown in Table 1.

Table 1. Descriptive Statistics

\begin{tabular}{|c|c|c|c|}
\hline Groups & Category & Group 1 & Group 2 \\
\hline Outdoor psysical activity & & $\begin{array}{c}\text { With particulates } \\
n=140(41.1 \%)\end{array}$ & $\begin{array}{l}\text { Without particulates } \\
n=201(58.9 \%)\end{array}$ \\
\hline \multirow{4}{*}{ Gender } & Male & $n=86(61.4 \%)$ & $\mathrm{n}=96(47.8 \%)$ \\
\hline & Female & $n=54(38.6 \%)$ & $\mathrm{n}=105(52.2 \%)$ \\
\hline & $20 s$ & $\mathrm{n}=13(9.3 \%)$ & $\mathrm{n}=34(16.9 \%)$ \\
\hline & $30 \mathrm{~s}$ & $\mathrm{n}=34(24.3 \%)$ & $\mathrm{n}=47(23.4 \%)$ \\
\hline \multirow[t]{5}{*}{ Age } & $40 \mathrm{~s}$ & $n=23(16.4 \%)$ & $\mathrm{n}=31(15.4 \%)$ \\
\hline & $50 \mathrm{~s}$ & $\mathrm{n}=39(27.9 \%)$ & $\mathrm{n}=49(24.4 \%)$ \\
\hline & $60 s+$ & $\mathrm{n}=31(22.1 \%)$ & $\mathrm{n}=40(19.9 \%)$ \\
\hline & Walking & $\mathrm{n}=38(27.1 \%)$ & $\mathrm{n}=52(25.9 \%)$ \\
\hline & Jogging & $n=34(24.3 \%)$ & $n=54(26.9 \%)$ \\
\hline \multirow{6}{*}{ Participated sport } & Cycling & $n=29(20.7 \%)$ & $\mathrm{n}=42(20.9 \%)$ \\
\hline & Badminton & $n=16(11.4 \%)$ & $\mathrm{n}=21(10.4 \%)$ \\
\hline & Basketball & $\mathrm{n}=15(10.7 \%)$ & $\mathrm{n}=19(4.0 \%)$ \\
\hline & Soccer & $\mathrm{n}=8(5.7 \%)$ & $\mathrm{n}=5(2.5 \%)$ \\
\hline & Rarely & $\mathrm{n}=41(29.3 \%)$ & $\mathrm{n}=31(15.4 \%)$ \\
\hline & Sometimes & $\mathrm{n}=30(21.4 \%)$ & $\mathrm{n}=39(19.4 \%)$ \\
\hline \multirow[t]{3}{*}{ Frequency of participation } & Often & $\mathrm{n}=27(19.3 \%)$ & $\mathrm{n}=47(23.4 \%)$ \\
\hline & Frequently & $n=29(20.7 \%)$ & $n=42(20.9 \%)$ \\
\hline & Very often & $\mathrm{n}=13(9.3 \%)$ & $\mathrm{n}=42(20.9 \%)$ \\
\hline \multirow{2}{*}{ Check weather forecast } & Yes & $n=140(100 \%)$ & $\mathrm{n}=147(73.1 \%)$ \\
\hline & No & $\mathrm{n}=0(0 \%)$ & $\mathrm{n}=54(26.9 \%)$ \\
\hline \multirow{2}{*}{ Mask for particulates } & With mask & $\mathrm{n}=103(73.6 \%)$ & $\mathrm{n}=49(24.4 \%)$ \\
\hline & Without mask & $\mathrm{n}=37(26.4 \%)$ & $\mathrm{n}=152(75.6 \%)$ \\
\hline
\end{tabular}

Legend: Group 1=outdoor physical activity with fine dust pollution; Group 2=outdoor physical activity withou fine dust pollution.

\section{Scale validity \& reliability}

An exploratory factor analyses was performed, using the PCA with Varimax of Participation Motives ( 7 factors, 24 items). Under Motives, the Kaiser Meyer-Olkin measure identified the sample adequacy for the analysis: $\mathrm{KMO}=.783$
(Field, 2009). Barlett's test of sphericity $(\chi 2=6863.810$, $\mathrm{df}=276, \mathrm{p}=.000$ ) was statistically significant. The seven extracted factors (Appearance, Psychological Condition, Physical Condition, Mastery, Competition, Enjoyment, and Affiliation) explained $84.36 \%$ of the total variance (Table 2 ). 
Table 2. Factor Structure Matrix for Participation Motives in Outdoor Physical Activities

\begin{tabular}{|c|c|c|c|c|c|c|c|}
\hline Items & 1 & 2 & 3 & 4 & 5 & 6 & 7 \\
\hline To maintain toned body & .952 & & & & & & \\
\hline To lose weight, look better & .943 & & & & & & \\
\hline To define muscle, look better & .936 & & & & & & \\
\hline To improve body shape & .862 & & & & & & \\
\hline Because it helps maintain a healthy body & & .939 & & & & & \\
\hline To improve cardiovascular fitness & & .925 & & & & & \\
\hline To maintain physical health & & .897 & & & & & \\
\hline Because it keeps me healthy & & .893 & & & & & \\
\hline Because it helps me relax & & & .934 & & & & \\
\hline To take my mind off other things & & & .924 & & & & \\
\hline To get away from pressures & & & .901 & & & & \\
\hline To cope with stress better & & & .889 & & & & \\
\hline Because I perform better than others & & & & .949 & & & \\
\hline To compete with others around me & & & & .945 & & & \\
\hline To work harder than others & & & & .901 & & & \\
\hline To get better at an activity & & & & & .949 & & \\
\hline To keep current skill level & & & & & .925 & & \\
\hline To obtain new skills/activities & & & & & .902 & & \\
\hline Because I have a good time & & & & & & .924 & \\
\hline Because it's interesting & & & & & & .918 & \\
\hline Because it makes me happy & & & & & & .849 & \\
\hline Because I enjoy spending time with others & & & & & & & .925 \\
\hline To be with friends & & & & & & & .902 \\
\hline To talk with friends while exercising & & & & & & & .787 \\
\hline E-value & 4.288 & 3.331 & 3.125 & 2.755 & 2.553 & 2.221 & 1.972 \\
\hline \multirow[t]{2}{*}{ Variance (\%) } & 17.86 & 13.87 & 13.02 & 11.48 & 10.63 & 9.254 & 8.215 \\
\hline & 6 & 9 & 2 & 1 & 8 & & \\
\hline
\end{tabular}

Legend: All Cronbach's alphas showed excellent internal consistency for reliability based on the .70 cutoff (Nunnally \& Bernstein, 1994): (a) Participation Motive (Appearance, $a=.948$; Psychological Condition, $\alpha=.934$; Physical Condition, $\alpha=.935$; Mastery, $a=.925$; Competition, $\mathrm{a}=.926$; Enjoyment, $\mathrm{a}=.882$; Affiliation $\mathrm{a}=.853$ )

\section{MANOVA}

The multivariate test revealed statistically significant differences in Participation Motives based on the fine dust concentration: (a) Motives [Wilks' lambda $=.707, \mathrm{~F}(7$, $333)=19.757, \mathrm{p}=0.00$, partial $\eta 2=.293]$. To find statistical results, an adjusted alpha level using a Bonferroni correction $(\mathrm{P}=0.05 / 7=.007)$ was applied. In participation Motives, univariate tests for (a) Competition, (b) Appearance, (c) Physical Condition, (d) Psychological Condition, and (e) Mastery were statistically significant (Table 3).

Table 3. Results of MANOVA: Differences in Participation Motives by Fine Dust Concentration

\begin{tabular}{llcccc}
\hline Source & DV & df & $\mathbf{F}$ & $\mathbf{p}$ & $\mathbf{n 2}$ \\
\hline Motives & Competition & 1 & 16.713 & $.000^{*}$ & .047 \\
& Appearance & 1 & 77.711 & $.000^{*}$ & .186 \\
& Physical condition & 1 & 10.753 & $.001 *$ & .031 \\
& Psychological condition & 1 & 16.815 & $.000 *$ & .047 \\
& Mastery & 1 & 19.785 & $.000 *$ & .055 \\
\hline
\end{tabular}

Legend: ${ }^{*} \mathrm{p}<0.007$.

Specifically, the mean scores of each factor based on groups are shown in Tables 4.

Table 4. Mean Scores of Motives Factors between Groups

\begin{tabular}{cccccccc}
\hline & $\mathbf{1}$ & $\mathbf{2}$ & $\mathbf{3}$ & $\mathbf{4}$ & $\mathbf{5}$ & $\mathbf{6}$ & $\mathbf{7}$ \\
\hline Group 1 & 4.140 & 4.532 & 3.421 & 4.293 & 3.416 & 4.260 & 3.890 \\
Group 2 & 3.506 & 3.188 & 3.657 & 3.782 & 4.046 & 3.536 & 4.020 \\
\hline
\end{tabular}

Legend: Group 1=outdoor physical activity with fine dust pollution, Group 2=outdoor physical activity without fine dust pollution; 1=Competition, 2=Appearance, 3=Affiliation, 4=Physical Condition, 5=Psychological Condition, $6=$ Mastery, $7=$ Enjoyment 


\section{Discussion}

This study deals with people's awareness of the danger of fine dust, which has emerged as a major social issue recently. Specifically, it analyzed people's motives when taking part in outdoor physical activities with varying levels of air pollutant concentration in the atmosphere, including fine dust. When considering the seriousness of the fine dust issue mentioned above, the importance of this study and the possibility of its contribution to relevant fields can be seen.

Along with basic demographic questions, basic questions about fine dust were asked (such as whether people checked the weather forecast for the fine dust concentration level before participating in outdoor physical activities and whether they wore anti-dust masks to block fine dust while doing outdoor physical activities). The respondents' answers were very interesting. The results showed that even though $100 \%$ of those who engaged in outdoor physical activities on days of severe fine dust concentration had checked the weather forecast for the fine dust level before going out and thus knew that the air was in a dangerous condition still participated in those outdoor physical activities. In addition, $26 \%$ engaged in outdoor physical activities without wearing anti-dust masks to protect them from fine dust. This percentage was higher than that for the group of people who engaged in outdoor physical activities on days with clean air without fine dust; such figures indicate that people are still not fully aware of the dangers of fine dust and the need to protect themselves against it. This result also reveals the need for the central or local governments of Korea to be more active in providing information that is more precise and detailed about the dangers of fine dust and the need to protect against it. Citizens of Korea should also be made more aware of the dangers of fine dust so that they can protect themselves in practical ways, concurrent with the government's protection measures, from the health risks of fine dust.

\section{Differences of participation motives according to fine dust}

The percentages for Competition, Appearance, Physical Condition, and Mastery were statistically higher in the motives of people who engage in outdoor physical activities on days of high fine dust concentration than of those who engage in such activities on days with clean air. These motives for participation are ones that bring about physical benefits or developmental benefits from physical activities. They are also motivators whose goals can be realized only with a relatively more continuous investment of time and effort than those of other factors, such as Affiliation, Enjoyment, and Psychological Condition. Kleiber, Larson, and Csikszentmihalyi (1986) explained that such activities are "serious physical activity," which requires a degree of effort above a certain level and brings about developmental benefits as a result. This explanation can be supported by the result of this study, which showed that most of the people who answered that they engage in physical activities more consistently to the question about the frequency of their physical activities were also those who continued to take part in outdoor physical activities on days with risky levels of fine dust. Thus, people who engage in physical activities more consistently and actively continue to do so on days of severe fine dust without changing their routine and taking proper protection measures, even though they are aware of the danger of fine dust. Such people need a better awareness of the risks of frequent exposure to fine dust over a long period, which are greater than the benefits they can derive from outdoor physical activities on days with high fine dust concentration.

By contrast, people who engaged in outdoor physical activities on the days of clean air answered that they did so for their mental well-being, which is in line with the results of other studies indicating that outdoor physical activities are helpful for stress relief (Henderson \& Bialeschki, 2008). Notably, the result of a study by Parfitt, Pavey, and Rowlands (2009), which revealed that physical activities have a positive influence on the psychological well-being of people in all age groups, can support the findings of this study. Recent studies have also revealed that modern people's sedentary lifestyle hampers their psychological health (Kobriger, J. Smith, Hollman, \& A. Smith, 2006). The group of people who engaged in outdoor physical activities on days with clean air reported a lower frequency of participation in response to the question about the frequency of their outdoor physical activities, but as argued by Dishman (2003), it is important to encourage people to take part in outdoor physical activities with proper protection measures and after checking the fine dust concentration levels, rather than encouraging them simply to raise their rate of participation in outdoor physical activities. In conclusion, due to the recent increase in the severity of air pollution, people need to take it into account when they engage in outdoor physical activities.

The results of this study are meaningful in that they can raise people's awareness about the health risks of fine dust, an issue of importance to society. The fact that people are not applying proper protection measures against fine dust even though they are aware of its danger demonstrates that people still do not have precise information about the health risks of fine dust. Even though previous studies have indicated that physical activities give physical, psychological, and social benefits, it may be necessary to re-examine whether outdoor physical activities in air filled with fine dust really does have more advantages than disadvantages. In addition, more proper protection measures and a greater understanding of the dangers of fine dust are necessary. The results of this study should not just remain as a research result, and further studies on the impact of fine dust on public health should be conducted.

The results and the experimental trial of this study are meaningful, but the study also has limitations. First, a long-term tracking study and massive data are needed to study air conditions and their impact on human health. Whereas cross-sectional data collected over a short period of time were used for this study, future studies will be able to produce results that are more accurate by applying a longitudinal research design. Second, this study is limited in terms of its analysis of people's complex decision-making processes and their awareness of the risk of fine dust, since it analyzed people's motives for engaging in outdoor physical activities only in relation to fine dust concentration levels. Once the constraints on people's outdoor physical activities are analyzed, for example, it may be possible to determine whether fine dust is actually one of the important factors constraining people's outdoor physical activities. Thus, future studies will need to include more factors. Third, this study was limited to Korea, where fine dust has recently emerged as a serious social problem. Results that are more meaningful could be generated by studies conducted in other countries, such as China or India, where the air pollution levels are the most serious in the world.

\section{Acknowledgements}

There are no acknowledgements. 


\section{Conflict of Interest}

The authors declare that there are no conflicts of interest.

Received: 21 February 2019 | Accepted: 23 April 2019| Published: 01 June 2019

\section{References}

Bandura, A. (1997). Self-efficacy: The exercise of control. New York, NY: Freeman.

Berry, H.L., Waite, T.D., Dear, K.B.G., Capon, A.G., \& Murray, V. (2018). The case for systems thinking about climate change and mental health. Nature Climate Change, 8, 282-290.

Dishman, R.K. (2003). The impact of behavior on quality of life. Quality of Life Research, 12, 43-49.

Egli, T., Bland, H.W., Melton, B.F., \& Czech, D.R. (2011) Influence of age, sex and race on college students' exercise motivation of physical activity. Journal of American College Health, 59(5), 399-406.

Field, A. (2009). Discovering statistics using SPSS (3rd ed.). Thousand Oaks, CA: SAGE Publications.

Frederick-Recascino, C., \& Morris, T. (2004). Intrinsic and extrinsic motivation in sport and exercise. In Morris, T. \& Summers, J. (Eds.), Sport Psychology: Theory, applications and issues (121-151). Australia: John Wiley \& Sons.

Gaston-Gayles, J.L. (2005) The factor structure and reliability of the Student Athletes' Motivation toward Sports and Academics Questionnaire (SAMSAQ). Journal of College Student Development, 46, 317-327.

Henderson, K.A., \& Bialeschki, M.D. (2008). Leisure and active lifestyles: Research reflections. Leisure Sciences, 27, 355-365.

Ingen, E.V., \& Eijck, K.V. (2009). Leisure and social capital: An analysis of types of company and activities. Leisure Sciences, 31, 192-206.

Jun, J., \& Kyle, G.T. (2011). Understanding the role of identity in the constraint negotiation process. Leisure Sciences, 33, 309-331.

Kang, H.H. (2016). Die rechtliche Untersuchung uber Feinstaub fur den Schutz des Gesundheitsrechts der Burger. Korean Environmental As sociation, 38(1), 159-193.

Kemperman, A.D.A.M., \&Timmermans, H.J.P. (2008). Influence of socio-demographics and residential environment on leisure activity participation. Leisure Sciences, 30, 306-324.

Kim, J., Dattilo, J., \& Heo, J. (2011). Education and recreation activities of older Asian immigrants. Educational Gerontology, 37, 336-350.

Kim, P.W. (2018). Operating an environmentally sustainable city using fine dust level big data measured at individual elementary schools. Sustainable Cities and Society, 37, 1-6.

Kleiber, D., Larson, R., \& Csikszentmihalyi, M. (1986). The experience of leisure in adolescence. Journal of Leisure Research, 18(3), 169-176.

Kobriger, S., Smith, J., Hollman, J., \& Smith, A. (2006). The contribution of golf to daily physical activity recommendations: How many steps does it take to complete a round of golf? Mayo Clinic Proceedings, 81, 1041-1043.

Korea Environment Corporation (2018). Reinforced Fine Dust (PM2.5) Standard as high as that of US and Japan. Retrieved 12/23, 2018, from http://www.me.go.kr/home/web/board/read. do? menuld=286\&boardMasterld=1\&boardCategoryld=39\&boar$\mathrm{dld}=849570$
Kwak, K. (2019). Invasion of fine dust, disease and coping methods. Retrieved 04/23, 2019, from http://www.civicnews.com/news/articleView.htmI?idxno=21216

Lloyd-Jones, D.M., Yuling, H., Labarthe, D., Mozaffarian, L.J., Appel, L., \& Van Horn, K. (2010). Defining and setting national goals for cardiovascular health promotion and disease reduction: The american heart association's strategic impact goal, through 2020 and beyond. Circulation, 121, 586-613. doi.org/10.1161/CIRCULATIONAHA.109.192703

Ministry of Environment. (n.d.). Fine dust control measures. Retrieved 12/12, 2018, from http://www.me.go.kr/issue/finedust4/

Molanorouzi, K., Khoo, S., \& Morris, T. (2014). Validating the physical activity and leisure motivation scale (PALMS). BMC Public Health, 14, 1074.

Mouratadis, M., Vansteenkiste, M., Lens, W., \& Sideridis, G. (2008). The motivating role of positive feedback in sport and physical education: Evidence for a motivational model. Journal of Sport and Exercise Psychology, 30, 240-268.

Murcia, J.A.M, Coll, D.G-C., Martin-Albo, J., \& Gimeno, E.C. (2010). Motivation and performance in physical education: An experimental test. Journal of Sports Science and Medicine, 9, 79-85.

Noh, H., Lee, S., \& Yu, J. (2018). Identifying effective fugitive dust control measures for construction projects in Korea. Sustainability, 10(4), 1206.

Ntoumanis, N. (2005) A prospective study of participation in optional school physical education using a self-determination theory framework. Journal of Educational Psychology, 97, 444-453.

Nunnally, J.C., \& Bernstein, I.H. (1994). Psychometric theory (3rd ed.). New York, NY: McGraw-Hill.

Parfitt, G., Pavey, T., \& Rowlands, A.V. (2009). Children's physical activity and psychological health: The relevance of intensity. Acta Paediatrica, 98, 1038-1043

Park, J., Park, E.H., Schauer, J.J., Yi, S-M., Heo, J. (2018). Reactive oxygen species (ROS) activity of ambient fine particles (PM2.5) measured in Seoul, Korea. Environment International, 117, 276-283.

Priest, N., Armstrong, R., Doyle, J., \& Waters, E. (2008). Interventions implemented through sporting organizations for increasing participation in sport. Cochrane Database of Systematic Review, 3, 1-15.

Roychowdhury, D. (2018). A comprehensive measure of participation motivation: Examining and validating the Physical Activity and Leisure Motivation Scale (PALMS). Journal of Human Sport and Exercise, 13(1), 231-247. doi.org/10.14198/jhse.2018.131.20

Stone, E.A., Yoon, S-C., \& Schauer, J.J. (2011). Chemical characterization of fine and coarse particles in Gosan, Korea during spring time dust events. Aerosol and Air Quality Research, 11, 31-43.

Trenberth, L., \& Dewe, P. (2002). The important of leisure as a means of coping with work related stress: An exploratory study. Counseling Psychology Quarterly, 15, 59-72.

Waldron, J.J., \& Dieser, R.B. (2010) Perspectives of fitness and health in college men and women. Journal of College Student Development, 51, 65 78.

Weiss, M.R., \& Ferrer-Caja, E. (2002). Motivational orientations and sport behavior. In T. S. Horn (Ed.), Advances in sport psychology (pp. 101-170). Champaign, IL, US: Human Kinetics.

Yonhap News (2019). Fine Dust (2) Worse or Better than in the past? Retrieved 1/23, 2019, from https://www.yna.co.kr/view/ AKR20190117053800502?input $=1179 \mathrm{~m}$ 